\title{
$2^{\text {th }}$ International Conference \\ ENGINEERING MECHANICS 2019
}

Svratka, Czech Republic, 13 - 16 May 2019

\section{AN INFLUENCE OF THE LOAD ON THE CAR GEARBOX NOISE}

\author{
E. Tomeh*
}

\begin{abstract}
Gearboxes are an integral part of the various devices, machines, cars etc. employed in a lot of branches of industry. It has to meet the certainty of individual components and, last but not least, reliability and durability. The paper focuses on the behaviour of these components following the noise under load level. Three experiments on different devices were conducted. The first test was on running conditions at device stand, the second test at Powertrain stand at Laboratories of Vehicles and Motors Department, TU of Liberec. The third one was performed in real traffic. The methods for following vibration diagnosis of cars gearbox are a modern instrument for controlling quality of assembly and manufacture of cars gearbox parts. Moreover, it has a big importance in solving the problems of noise and vibration of automobile gearbox.
\end{abstract}

Keywords: Gearbox, vibration, noise, frequency, amplitude, order

\section{Introduction}

Each automobile gearbox which uses gearings for changing the gear ratio produces a certain noise level. This feature is one of the important aspects for evaluation of the whole vehicle quality. It can be assessed by a lot of customers without any expertise in this research field. The noise level generally belongs among the most commonly occurring negative impacts on the product quality, not only in engineering. Vibration of an automobile gearbox is closely connected with the insufficient quality of the designed construction and the production accuracy.

Noise can be described quantitatively or qualitatively. Quantitative variables are those that can be measured (amplitude, frequency, etc.) and are defined by numeric values. Qualitative variables include subjective evaluation and are defined by different standards and other prescribed methodologies.

The goal of the experiment on the gearbox includes: noise analysis and following the main vibration exciters during operation on the second and the fifth gear at acceleration mode. The main parts of the gearbox are represented by gears, shafts and bearings. When calculating the excitation frequency of gearbox, the values of the frequency spectrum harmonic components and values of their amplitudes are deducted from the measured values. One of the major vibration exciters in gearbox is the engagement of gears, which is the subject of this article.

\section{Methods}

The gearbox response was evaluated basing on frequency analysis values having three ways. In all types of experiments, the tested object was examined in the same conditions. In the case of the one gearbox, the accelerometer was cemented by the use of glue, the vibration analyser was attached to the connector. The second and fifth gears were followed under acceleration (driving force of engine). Measurements were made only on these two gears as they are often problematic in terms of noise. The position of the accelerometer on the gearbox was the same for the all three measuring modes (Tomeh, 2016).

Doc. Dr. Ing. Elias Tomeh: Faculty of Mechanical Engineering, Technical University of Liberec, Studentská 1402/2; 461 17, Liberec; CZ, elias.tomeh@tul.cz 
The first measurement stage was carried out using device stand. The spectrum of order analysis, supplemented by frequency spectra, were employed. The gearbox was placed in the device stand by a handling crane so that a drive is connected to the drive shaft, other shafts are connected to the output shafts of the differential (driveshaft). The advantage of this method is a greater detection of faults, since the gear is not subject to surrounding influences, as it is the case with driving tests. The gear faults are then more visible. Figure 1 shows the location of the sensors on the gearbox (Tomeh, 2015).

The test was conducted at three values of moment of force 15, 30, $45 \mathrm{Nm}$. The second gear was loaded at $1809 \mathrm{RPM}$ (about $50 \mathrm{~km} / \mathrm{h}$ ) and $3941 \mathrm{RPM}$. The fifth gear was examined almost at the same RPM i.e. (1815 RPM and 3946 RPM).

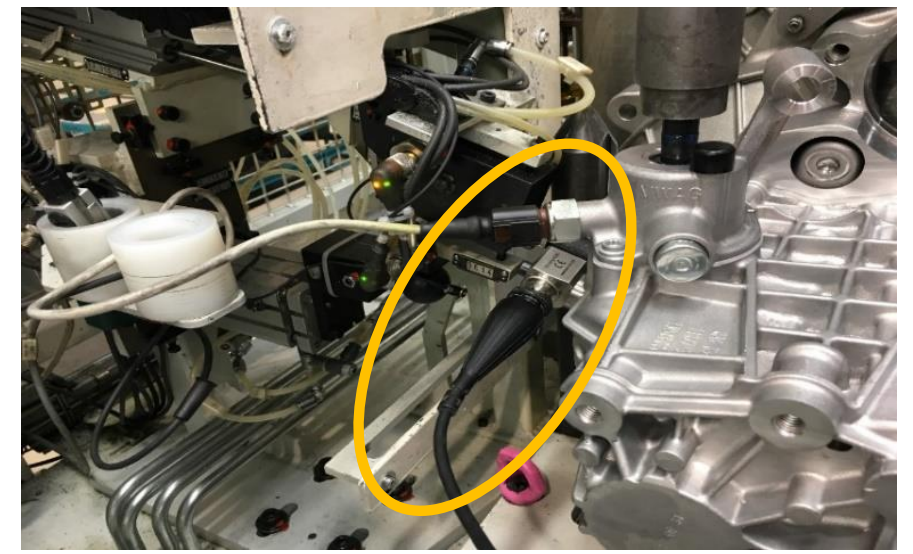

Fig. 1: The location of the sensors on the gearbox at the device stand.

Fig. 2 shows the order of the SK3 differential at a loading of $40 \mathrm{Nm}$. Vertical dotted lines show the harmonic components of the fifth gear differential. In comparison to the second gear tested at $30 \mathrm{Nm}$, the noise level of the first harmonic component (77th order) increased by approximately of $20 \mathrm{~dB}$. The second to fifth harmonic components do not exceed the first. It can be assumed, that at bigger loading on the permanent gear transmission, the clearance will be better defined and the deviation in the misalignment will be reduced.

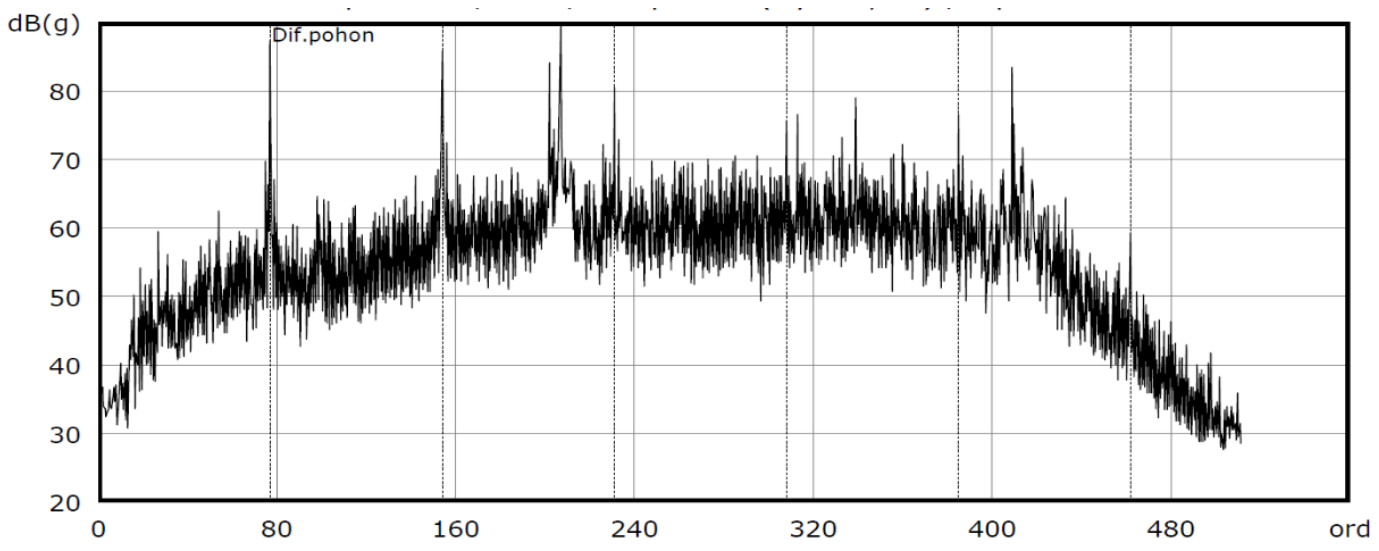

Fig. 2: Spectrum of noise from vibration of differential SK3, measured by Order Analysis. Testing at device stand.

Besides of the device stand, the gearbox was tested in the KVM Powertrain stand laboratory. This test was carried out in the Technical University of Liberec. The Powertrain stand is recommended for testing gearbox, and optimizing the parameters of the car's gearbox. Moreover, the long-term tests for simulations of real traffic can be elaborated.

The measured gearbox was identical to the gearbox measured at device stand. At this Powertrain stand, the gearbox is firmly screwed to the frame and to the 1.4 MPI engine with a power of $55 \mathrm{~kW}$. The gearbox control is provided by robots which means clutch pedal control and robotic hand gear shift. The Powertrain stand of the KVM laboratory is shown in Figure 3. The gearbox was tested at two modes expressed by 1815 RPM and 3941 RPM, at a load of 30, 45 and 70 Nm (Tomeh, 2015). 


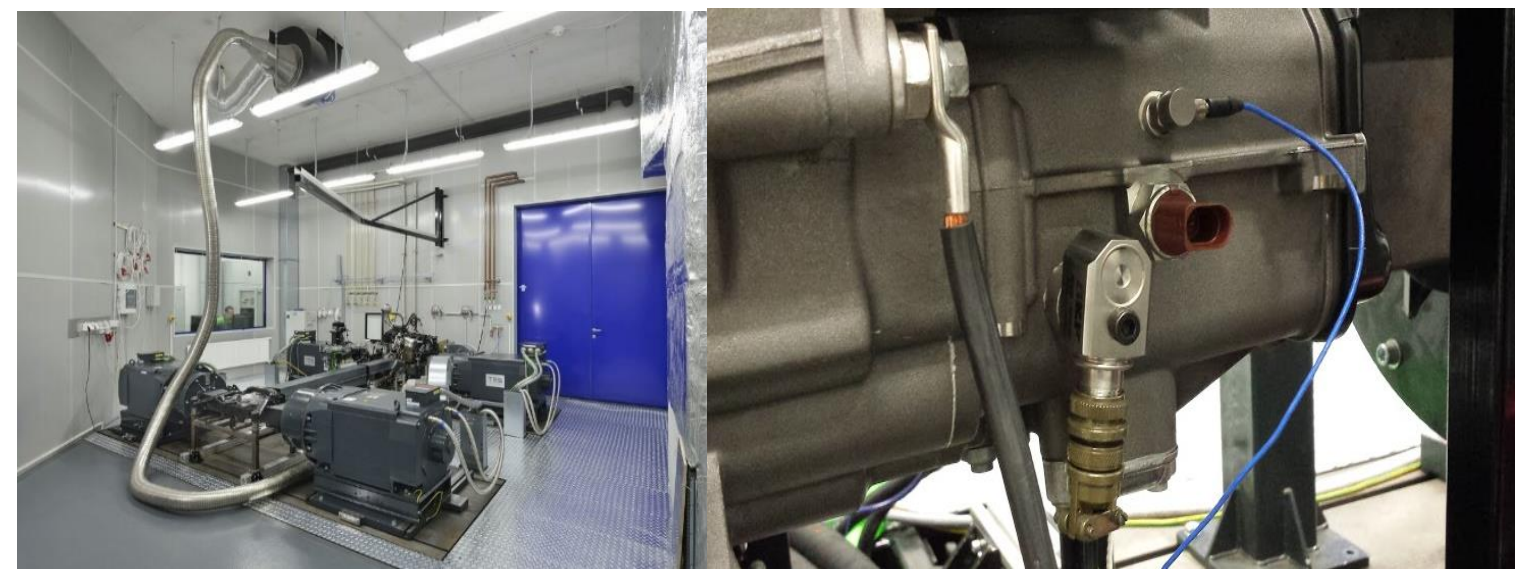

Fig. 3: Powertrain stand in KVM TUL laboratories and position of acceleration sensor on the gearbox.

Figure 4 shows that the amplitudes of the gear mesh frequency of the second gear and the permanent gear transmission are negligible. Only the first harmonic component was recorded. The other components are negligible in size. The spectrum shows no unusual anomalies in terms of amplitude. The gear mesh frequency $(665.6 \mathrm{~Hz})$ is indicated by the cursor. Its amplitude at moment of force $70 \mathrm{Nm}$ has a value of $0.14 \mathrm{~g}$. The gear mesh frequency of the permanent gear transmission is $247 \mathrm{~Hz}$ with a low amplitude value of $0.05 \mathrm{~g}$.

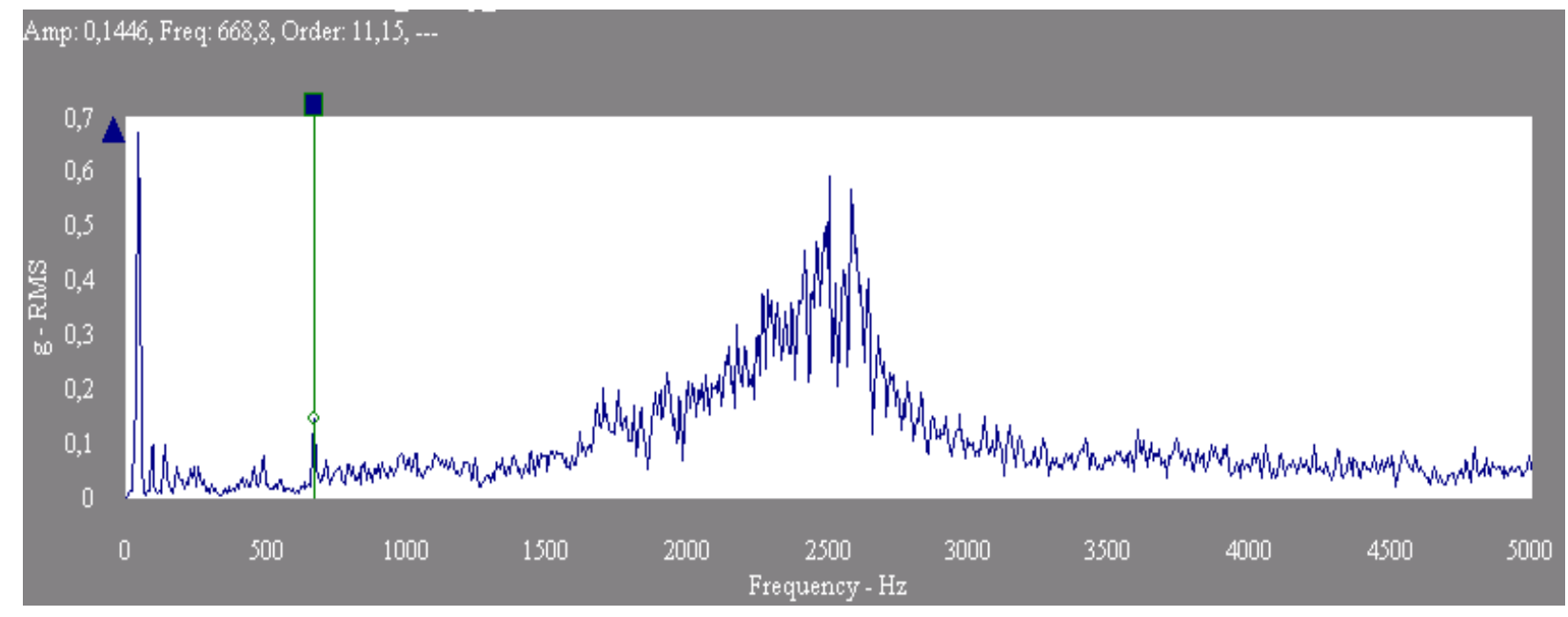

Fig. 4: Second gear level spectrum of vibration, measured at loading of $70 \mathrm{Nm}$ and 1815 RPM. Testing on Powertrain stand in KVM TUL laboratories. Root Mean Square RMS = 3,25Gs.

The last test of the gearbox was in real traffic, around the town of Liberec. The gearbox was placed in a car with a motor capacity of $1.0 \mathrm{~cm}^{3}$ and a power of $44 \mathrm{~kW}$. The cable was attached to the body of the car by means of a paper adhesive tape and inserted into the car cab, between the rubber seal and the front door. The speed, the number of engine rotations, torque and throttle setting angle were monitored online, using the computer. The speed and torque setting were decisive, ideally the same as in Vehicles and Motors Department Laboratories at the Powertrain stand measuring station.

The shot of the permanent gear transmission enters the spectrum of the fifth gear, as can also be seen in the mix channel order spectrum of the fifth gear (see Figure 5). The amplitude of the first harmonic component of the permanent gear transmission stands out up to 20.09 order. This value is obtained by dividing the number of final drive gear teeth by the total gear ratio of the fifth gear: $77 \div 3.832=20.09$ (order).

There are two distinct orders in the spectrum (see Figure 5). On 54th order there is a significant amplitude of the fifth gear drive gear. The difference 20.09 order from the surrounding bands is approximately $14 \mathrm{~dB}$. This is a difference that even an undemanding customer will notice. However, these are results from the sensor. The values from the microphone in the car cab may be different. The car cab space is affected by other sources of noise, such as the drive unit, the body, etc.

Figure 6 shows an order spectrum from a microphone located in the car cab. The spectrum is measured at 3370 RPM. 


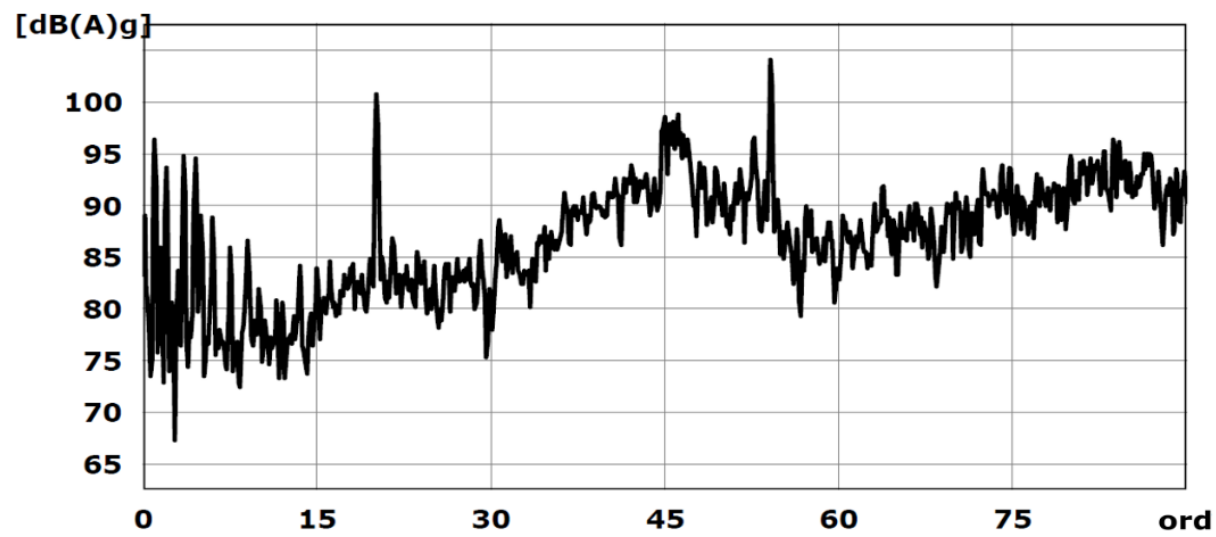

Fig. 5: Fifth gear level spectrum of vibration, measured by Order Analysis testing at loading $70 \mathrm{Nm}$ and 3920 RPM in real traffic. Sensor output.

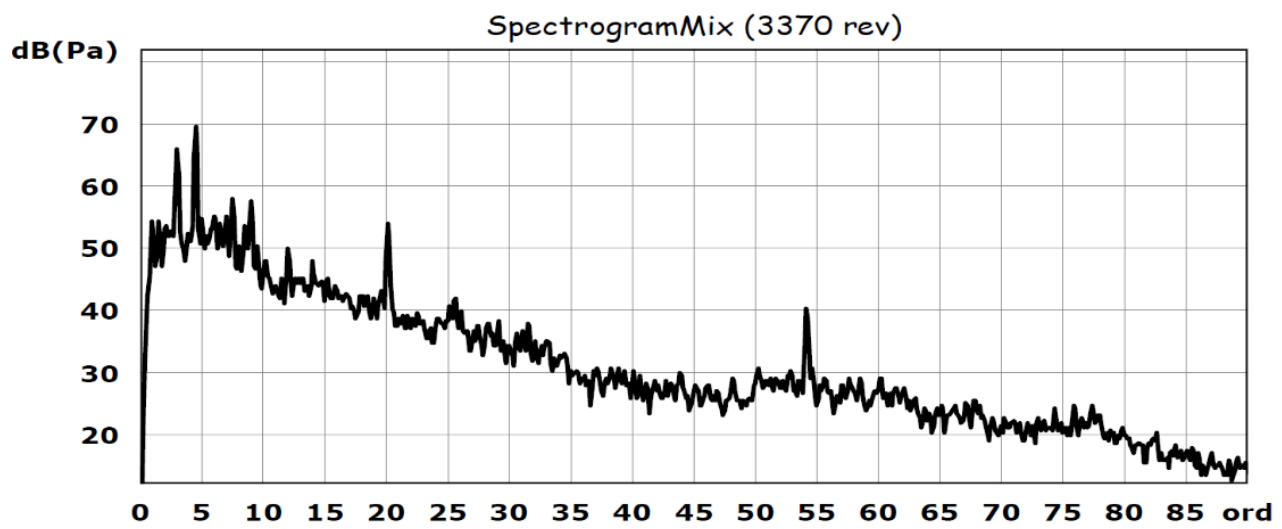

Fig. 6: Fifth gear level spectrum of vibration, measured by Order Analysis testing at loading $70 \mathrm{Nm}$ and 3370 RPM in real traffic. Microphone output.

\section{Conclusions}

The aim of the research was to evaluate the influence of the load on the noise of the automobile gearbox. Vibration measurements for the second and fifth gear are captured. On the device stand, it was not possible to reach a load of $45 \mathrm{Nm}$ for the second gear because of overheating of the DC motors, their control and regulation. Also, this test is very different from the actual operation of the gearbox, its different fixation to the frame of the running gear, compared to the car mount. The measurement process at Powertrain stand is closer to real traffic. The gearbox was powered by a combustion engine and the loading on the semi-shafts was controlled by dynamometers. In the last phase of the measurement, the gearbox was in real-life conditions that were limited by the traffic, and then the search for a suitable road inclination to achieve individual loads at certain engine speeds.

All three methods of measurement confirmed a reduction of vibration and noise with increase of loading.

\section{Acknowledgement}

The paper is elaborated with financial support of Technical University of Liberec in the framework of specific university research competition.

\section{References}

Tomeh, E. (2007) Diagnostic Methodology of Rolling Element and Journal Bearings. Textbook, Technical university of Liberec.

Tomeh, E. (2015) Technical Diagnostic - Vibration diagnostics of Machines and Equipment. Textbook, Technical university of Liberec (in Czech).

Tomeh, E. (2016) Possibilities for Reducing Car Gearbox Vibration and Noise. In.: Advances in Mechanism Design II - Proceedings of the XII International Conference on the Theory of Machines and Mechanisms. Technical university of Liberec, pp 255 - 262. 